\title{
Projeto Música nas Escolas de Barra Mansa: a prática de instrumentos no processo de educação musical nas escolas públicas
}

Vantoil de Souza Junior

Universidade Federal do Rio de Janeiro - UFRJ; Mestrado em Música. 


\section{Resumo}

Este artigo apresenta os principais aspectos do ensino coletivo de instrumentos musicais, aplicados nas escolas públicas de Barra Mansa, através do projeto denominado Música nas Escolas de Barra Mansa. A prática desenvolvida nas unidades educacionais do Município de Barra Mansa faz parte do projeto de pesquisa de mestrado em curso, cujo tema é a educação musical, com foco na musicalidade abrangente. Foram analisados os dados do Projeto desenvolvido no município de Barra Mansa - RJ, com ênfase nos resultados efetivamente obtidos pelo processo aplicado, que se tornou uma das referências em educação musical através do ensino coletivo de instrumentos.

Palavras-chave: Educação Musical. Ensino Coletivo. Banda Sinfônica. Orquestra Sinfônica. Musicalidade Abrangente.

\section{Abstract}

This article intends to present the main aspects of instrumental group teaching, developing at public schools of Barra Mansa City, by a Project called Music at Schools of Barra Mansa. The pratice developed at educational unities at Barra Mansa City is part of a Project for master degree where the theme is musical educacion and the Comprehensive Musicianship. The data of the Project developed in the city of Barra Mansa - RJ were analyzed, with emphasis on the results effectively obtained by the applied process, that became one of the references in musical education through the collective teaching of instruments.

Keywords: Music Education. Group Teaching. Simphonic Band. Simphonic Orchestra. Comprehensive Musicianship. 


\section{Introdução}

Este artigo relata parte do trabalho de observação, realizado para o projeto de pesquisa de mestrado, em andamento na área de Educação Musical, tendo como foco a sistematização dos processos de musicalização em escolas públicas, analisando o ensino coletivo de instrumentos musicais, como uma das principais ações de educação desenvolvidas nas escolas públicas do município de Barra Mansa-RJ.

Segundo Cruvinel (2005) o aparecimento do ensino coletivo no Brasil se deu no período colonial, através das bandas de escravos, seguindo o desenvolvimento com bandas, fanfarras e, com grupos de samba e choro. Cruvinel (2005) aponta para a inexistência de um processo de sistematização, sendo o modelo de ensino totalmente apoiado na educação não-formal. Fischer (2010) aponta que o surgimento de projetos sociais baseados no ensino da música disseminou mais ainda o processo não formal de educação, oferecendo o aprendizado musical como oportunidade para as crianças e Jovens Atendidos. O processo permite, segundo Fischer (2010), o surgimento de grupos orquestrais de diversos níveis.

Souza Junior (2015) aponta diversos efeitos advindos do processo de educação musical desenvolvido no município de Barra Mansa, sendo de natureza cultural, educacional e social. Para Souza Junior (2005) o processo de educação musical, quando desenvolvido no âmbito de projetos sociais, deve guardar a preocupação de não se transmutar em terapia ocupacional. Antes, deve proporcionar qualidade técnica tal que permita ao aluno atendido o desenvolvimento completo de suas habilidades e, o consequente ingresso no mercado de trabalho. A inserção do processo não formal de ensino coletivo de instrumentos, na estrutura das escolas públicas, e a sistematização desse processo são temas tratados por Souza Junior (2015). Fischer (2012), discutindo os projetos sociais com programas de formação musical, aponta como um dos exemplos brasileiros o Projeto Música nas Escolas de Barra Mansa, destacando a qualidade dos grupos oriundos do programa de formação implantado.

O processo implantado em Barra Mansa tem como principal característica a implementação do modelo não formal de ensino de música no ambiente formal das escolas. A fragmentação, comum nos processos formais desenvolvidos nas escolas, acaba por dificultar a percepção ampla da música pelo aluno. Alvares (2016) assevera que “nessa fragmentação, muitas vezes, perde-se a noção do todo e os alunos tendem a não 
perceber as semelhanças e relações entre as diferentes áreas do conhecimento" (ALVARES, 2016, p. 96).

A proposta do Projeto Música nas Escolas apresenta um processo de reunificação do saber, em que a prática instrumental busca permitir ao aluno o conhecimento amplo, que vai encontrar a fragmentação nos períodos avançados, quando o aluno já está totalmente imerso na prática musical. A musicalidade abrangente, segundo Alvares (2016), "reconhece a fragmentação nas práticas educacionais atuais, propondo a reunificação do saber, descrevendo um processo de transdisciplinaridade na educação musical" (ALVARES, 2016, p. 97).

\section{O Projeto Música nas Escolas de Barra Mansa}

Iniciado em 2003, com a estruturação de uma pequena banda de metais existente numa unidade escolar, o Projeto Música nas Escolas de Barra Mansa é um exemplo de processo de sistematização do ensino de música. Aplicado inicialmente em 2 escolas, com atendimento direto, oferecido a 600 alunos, o modelo se desenvolveu e, atualmente, atende a todas as unidades escolares do município de Barra Mansa - RJ. A transformação das escolas em polos de prática instrumental permitiu o desenvolvimento de centros de difusão da educação musical, gerando inúmeras formações orquestrais.

No processo de desenvolvimento musical apresentadondo a prática instrumental acaba por permitir o surgimento de grupos estáveis, transformando a estrutura das escolas públicas em polos de difusão musical, com intensa participação dos alunos. Dentre os grupos surgidos no projeto destacam-se:

. Orquestra Sinfônica de Barra Mansa

. Banda Sinfônica

. Orquestra de Metais

. Orquestra de Jazz

- Grupo de Percussão

. Orquestra Sinfônica Infanto-Juvenil

. Banda Sinfônica Infantil

- Camerata de Cordas

- Bandas de Música das unidades escolares 
A Orquestra Sinfônica de Barra Mansa, principal formação do Projeto Música nas Escolas de Barra Mansa, foi criada a partir do desenvolvimento de práticas musicais avançadas com os alunos atendidos, em 2005, tornando-se, posteriormente, Centro do processo de formação, reunindo professores, monitores e alunos avançados. $\mathrm{O}$ conjunto já se apresentou nos principais palcos do país e mostra o poder do processo baseado na Musicalidade Abrangente ao receber solistas das mais variadas vertentes, que vão desde vencedores de concursos internacionais aclamados, até grandes ícones da música popular brasileira. Nos últimos anos, a orquestra acompanhou as principais companhias de balé do mundo, iniciando em 2011 com o Balé do Theatro Mariinsky, de São Petesburgo Rússia, antigamente conhecido como Balé Kirov. Em 2012, acompanhou o Corpo de Baile do Theatro Alla Scala, de Milão - Itália e, em 2014 recebeu novamente o Balé do Theatro Mariinski. Finalmente, em 2015, acompanhou o Balé Bolshoi, aclamada companhia de Moscou - Rússia.

A Banda Sinfônica desenvolve extensa programação, disseminando os maiores compositores mundiais, cuja obra é dedicada a essa formação. Um dos principais resultados da Banda Sinfônica é a preparação de instrumentistas de sopro e percussão com grande qualidade técnica. Essa característica acaba se repetindo nos demais grupos do projeto, como resultado do processo de formação desenvolvido.

A Orquestra de Jazz permite ao aluno o desenvolvimento da improvisação musical. O grupo foi criado para apresentar aos alunos uma das vertentes da música dita "popular". Os concertos didáticos realizados levam os alunos ao contato direto com a linguagem do Jazz.

A Camerata de Cordas, formada por alunos intermediários do processo de prática instrumental, é uma das possibilidades de prática de música de câmara oferecidas pelo projeto. É passagem obrigatória para os alunos dos polos de cordas friccionadas, antes de ingressarem na Orquestra Sinfônica de Barra Mansa.

A Orquestra de Metais, também conhecida como Banda Marcial de Barra Mansa, é fruto da transformação do grupo existente no município antes do início do projeto. A pequena banda marcial, com extrema dificuldade estrutural e sem qualquer fundamento pedagógico, se transformou no mais importante grupo de metais e percussão do país, fazendo inúmeras estreias de obras de compositores brasileiros e estrangeiros. 
A música de câmara é praticada pelos alunos por meio de inúmeras formações fomentadas pelo projeto. São duos, trios, quartetos, quintetos, formados pelos alunos de diversos níveis, permitindo seu crescimento musical e o desenvolvimento da capacidade de prática musical em conjunto.

\section{A estrutura pedagógica do Projeto Música nas Escolas de Barra Mansa}

Segundo Souza Junior (2015), a proposta do Projeto Música nas Escolas de Barra Mansa divide o processo de formação em duas áreas amplas:

\section{. Conteúdo Obrigatório}

. Conteúdo Optativo

O Conteúdo obrigatório é desenvolvido nas salas de aulas, como parte do conteúdo "música", apresentado aos alunos em atividades dentro do horário letivo. É dividido em:

. Musicalização na Educação Infantil

. Musicalização nos Anos Iniciais do Ensino Fundamental

. Apreciação Musical para os anos finais do Ensino Fundamental

Todo o processo é desenvolvido com atividades de percepção musical, canto, criação musical e práticas percussivas.

O Conteúdo Optativo é desenvolvido no contra-horário letivo, com prática de instrumentos variados. O projeto oferece formação dos seguintes instrumentos:

Sopros: Flautim, flauta, oboé, clarineta, fagote e, saxofone.

Metais: Trompa, trompete, trombone, eufônio e, tuba.

Percussão: Tímpanos, xilofone, vibrafone, marimba, campana tubular, glockenspiel, celesta, percussão orquestral e percussão brasileira.

Teclados: Piano.

Cordas: Violino, viola, violoncelo, contrabaixo, harpa e, violão. 
O processo é todo baseado no ensino coletivo e, somente nos períodos mais avançados o aluno recebe formação com aulas individuais.

Atualmente, o projeto atende às escolas públicas com um processo que tem início na Educação Infantil. Nesse processo, o ensino se baseia no desenvolvimento de uma percepção ampla da música, com práticas voltadas para a percepção musical e da coordenação motora, atuando como importante instrumento de desenvolvimento do processo cognitivo. É um processo continuado, que segue até os anos iniciais do Ensino Fundamental.

\section{A formação do profissional para atuação no projeto}

O principal desafio dos projetos sociais com ênfase na prática musical é a falta de pessoal qualificado. O Projeto Música nas Escolas de Barra Mansa, em seu início, não logrou encontrar oferta de pessoal qualificado, com formação acadêmica. A implantação do projeto partiu da contratação de 5 músicos da região, com experiência prática em banda de música.

Essa falta de pessoal com formação acadêmica foi argumento utilizado pelo Ministério da Educação quando do embasamento das Razões do Veto Presidencial ao art. 2ª da Lei 11.769/08 (BRASIL, 2008), em que o corpo técnico do Ministério apontou a existência de saberes não formais que, apesar da falta da chancela acadêmica, eram constituídos de grandes mestres nas diversas práticas musicais em cada região. Contudo, o próprio ministério orienta a necessidade de conduzir o processo de formação musical de modo a permitir a formação acadêmica dos profissionais envolvidos.

A solução encontrada pelo projeto foi oferecer formação continuada com professores de alta qualidade e, paralelamente, estabelecer parcerias com entidades acadêmicas formais, que ofertassem a formação acadêmica aos monitores. $\mathrm{O}$ primeiro convênio celebrado foi com o Centro Universitário de Barra Mansa - UBM, com a implantação dos cursos de bacharelado em música e licenciatura em música. Posteriormente, o mesmo Centro Universitário de Barra Mansa ofereceu pós-graduação em música, ampliando a capacitação dos profissionais envolvidos no projeto. 
Recentemente, a Orquestra Sinfônica de Barra Mansa celebrou convênio com a Universidade Federal do Rio de Janeiro - UFRJ, para o Mestrado Profissional em Música. Com tal convênio, os alunos do Projeto Música nas Escolas de Barra Mansa podem planejar sua formação, que tem início nas creches e na Educação Infantil, indo até o mestrado em música.

Assim, o projeto implantado em Barra Mansa conseguiu solucionar o problema da falta de qualificação, permitindo maior crescimento técnico dos alunos e monitores. Contudo, o resultado não se restringiu ao Projeto Música nas Escolas, antes, gerou uma excelente mão de obra qualificada na região, permitindo a diversas instituições o acesso a profissionais qualificados para o ensino musical. Dessa forma, o processo não formal acabou por gerar um excelente resultado para o processo formal.

\section{Considerações finais}

Os resultados verificados até o momento em Barra Mansa tiveram início na implantação de um modelo não formal em ambientes com estruturas preparadas para o ensino formal. Essa mistura permitiu o desenvolvimento de um padrão que vem sendo replicado em várias cidades.

O modelo já permitiu um grande desenvolvimento da educação musical oferecida na região sul fluminense. Contudo, verifica-se ainda uma grande necessidade de estruturas capazes de abrigar os resultados dos projetos de formação musical que estão surgindo nas diversas cidades. Também, verifica-se a necessidade de uma revisão constante no programa oferecido pelo Projeto Música nas Escolas de Barra Mansa, para que o momento da fragmentação ocorra com a mesma qualidade do processo amplo inicial. Essa necessidade tem levado os gestores a revisarem os programas para que o aluno chegue ao conteúdo avançado totalmente preparado para o ingresso na realidade acadêmica, que permitirá um desenvolvimento ainda maior do que o experimentado.

São as práticas não formais permeando o ambiente acadêmico, permitindo o desenvolvimento contínuo das estruturas pedagógicas do ensino musical. 


\section{Referências}

ALVARES, Sérgio Luís de Almeida. Considerações sobre a educação musical na diversidade sob a perspectiva da Musicalidade Abrangente. In Educação musical na diversidade: construindo um olhar de reconhecimento humano e equidade social em educação. ALVARES, Thelma Sydenstricker e AMARANTE, Paulo (orgs.). Curitiba, Ed. CRV, 2016.

BRASIL. Lei 11.769, de 18/08/2008. Altera a lei no 9.394/96, de 20 de dezembro de 1996, Lei de Diretrizes e Bases da Educação Nacional para dispor sobre a obrigatoriedade do ensino de música na educação básica. Presidência da República. Casa Civil. Subchefia para Assuntos Jurídicos. Brasília, 2008. Disponível em <http://www.planalto.gov.br/ccivil_03/_Ato2007-2010/2008/Lei/L11769.htm>. Acesso em: 01/08/2016.

CRUVINEL, Flavia Maria. O ensino coletivo de instrumentos musicais na educação básica: compromisso com a escola a partir de propostas significativas de ensino musical. Disponível em: mhttp://www.jacksonavitraz.com.br/abemco. ida.unb.br/admin/uploads/pdf/form2_flavia_cruvinel.pdf. Acesso em 25 de março de 2015.

FISCHER, Heloísa. Dossiê "Cidadania Sinfônica”. Anuário Viva Música!, VivaMúsica! Edições, Rio de Janeiro, 2012.

SOUZA JUNIOR, Vantoil de. Projeto Música na Escola: inovação e eficiência no ensino fundamental e médio. Congresso Internacional de Gestão de Inovação da Educação do Setor Público. Ministério da Educação. Brasília - DF, 2015. Disponível em: https://www.youtube.com/watch?v=aUbhdURT34w. Acesso em 21 de julho de 2017. 